\title{
Health and Social Care in the community
}

Co-creation of services to maintain independence and optimise wellbeing: learnings from Australia's Older Women Living Alone (OWLA) project

\begin{tabular}{|r|l|}
\hline Journal: & Health \& Social Care in the Community \\
\hline Manuscript ID & HSCC-OA-19-0102.R2 \\
\hline Manuscript Type: & Original Article \\
\hline Keywords: & $\begin{array}{l}\text { Action Research, Ageing, Community Participation, Gender and } \\
\text { Community Care, Health Inequalities, Living alone }\end{array}$ \\
\hline \multicolumn{2}{|l}{} \\
\hline
\end{tabular}


For many populations at risk of social isolated, including Older Women Living Alone (OWLA), existing services to maintain independence and optimise wellbeing are difficult to access, unsuitable or unavailable. Co-creation is a strategy to develop 'person-centred' services that meet the needs of individuals. We adapted an existing framework for co-creation and used participatory action research methods, supported by an evidence base comprising a systematic review, analysis of routinely collected data and interviews, to develop person-centred services for OWLA. This approach achieved co-creation through an iterative process of consultation and review, involving a series of facilitated discussions with women living alone and stakeholders.

A total of 13 women living alone, aged $\geq 55$ years, and eight stakeholders representing service providers and advocacy groups, were recruited to participate in these discussions. Sessions with between three and five OWLA, were held across Melbourne. The information was compiled and presented to service stakeholders in a single facilitated forum, held in central Melbourne. Smaller facilitated sessions with OWLA followed, to review and discuss the collated service stakeholder input. The information from these OWLA sessions were again compiled and directed back to the service stakeholders for consideration and further discussion. The two groups came together for a final forum to prioritise the co-created ten services that they believed would be feasible and would address unmet need to support OWLA maintain independence.

The process of co-creation was time-consuming and required considerable preparation to facilitate input from the target population. Small groups, gathering at convenient local locations, with transport support were essential in removing barriers to participation. However, co-creation was a viable method of eliciting the women's preferences and developing services more likely to meet their needs. 


\section{What is known about this topic:}

- For populations at risk of social isolation such as Older Women Living Alone (OWLA), services to enhance wellbeing and maintain independence may be difficult to access, unsuitable or unavailable

- Co-creation is a strategy aimed at developing interventions meeting the needs of individuals.

- The specific actions, tools and behaviours involved in co-creation are currently unclear.

\section{What this paper adds:}

- This paper provides an outline of the process of co-creation, including adaptations to support participation.

- For researchers, the process of co-creation can be time-consuming and requires considerable preparation to facilitate productive engagement and participation from the target population.

- Co-creation benefits from small groups, convenient local locations, and financial / logistical support for transportation. 


\section{Introduction}

Current health systems are fundamentally misaligned to the needs of older people (WHO, 2015). To achieve alignment, a clearer understanding of health in older age and what can be done to improve it are needed (WHO, 2015). To that end, consideration of the social aspects of older people's lives is critical. Social isolation and loneliness have a significant impact on health and wellbeing, with living alone a predictor of social isolation in community dwelling older people (Iliffe et al., 2007). For Older Women Living Alone (OWLA) existing services that maintain wellbeing and independence may be difficult to access, unsuitable or unavailable. Services that are accessible, available, acceptable, affordable, adequate and of which they are aware is required to support OWLA (Feldman \& Radermacher, 2016; Saurman, 2015). Restructuring services is insufficient (The King's Fund, 2013). Rather, a new way of working with OWLA and health and aged care staff must be developed comprising full and equal partnership with service users, other organisations and the wider community; that is, co-creation (Boyd, McKernon, \& Old, 2010; The King's Fund, 2013).

To adopt a person-centred approach to meet the needs of OWLA, an existing co-creation framework was adapted to structure person-centred development of services, implementing the co-creation process through a participatory action research (PAR) approach. We describe the background for co-creation, a brief description of PAR, a description of the context of the current project, followed by the project aims, key elements, methods, results, practical recommendations and challenges and limitations for using this approach. Our experiences may assist others to operationalise personcentred approaches to improving relevant health and wellbeing outcomes for other vulnerable populations and in other contexts. 


\section{Co-creation}

Co-creation, that is, involving consumers in the development of goods and services, has been used in the business sector for many years to improve products and thereby increase consumer uptake (Gustafsson, Kristensson, \& Witell, 2012). This approach has slowly spread to other fields, being adapted and used in design science as experience-based co-design, computer sciences as technology co-design and community development as participatory research (Greenhalgh, Jackson, Shaw, \& Janamian, 2016). The evolution of marketing theory encapsulates the evolution of the needs of community members over time, aligning with the changes in societal norms and ultimately leading to the development and inclusion of co-creation in the business sector. Therefore, it is useful to describe how co-creation came about from the perspective of this sector. Vargo and Lusch (2004) summarised this evolution succinctly. Early theory, accepted until around 1920, proposed that wealth in society was created through the acquisition of material goods. Until around the 1950s, while there was still a focus on acquisition of goods, embedding value was becoming evident. This involved the identification that customers do not buy things solely based on need, but to achieve fulfillment, and customer satisfaction became the goal of marketing. This notion was prominent until the 1980s. At this point, marketing became viewed as a continuous social and economic process, with the customer always as a coproducer. As the focus became service-centred, and thereby inherently customer oriented and relational, service providers assisted community members in the process of value creation, where there was value for all parties. All stakeholders shared in the creation of value, that is value co-creation, including both monetary and other, with and for all affected and involved. As the focus was on creation of value with stakeholders, the term cocreation was utilised (Janamian et al., 2016). The aim was to develop sustainable long-term relationships as well as enhancing economic and societal benefits. Other fields have built on this work; with Greenhalgh et al. (2016) comparing the methods from business and marketing, computer science, design science and community development with a view 
to applying co-creation to achieve research impact across community-based health services. Of note, the term co-design is used to describe these approaches, shifting the emphasis away from conveying the actual value creation contribution, to the process of involving stakeholders to develop or improve a service or product, potentially including the use of design tools (Donetto, Tsianakas, \& Robert, 2014). Key principles that were included in all successful models reviewed were: (1) a complex adaptive system approach, where there was an assumption of emergence, adaptation to local context, and that the process would be nonlinear; (2) research was viewed as a creative enterprise, where the experience of the participants was central; and (3) process was just as important as that which was generated as a result of the co-creation (Greenhalgh et al., 2016).

\section{Undertaking co-creation in the health sector}

It has only been relatively recently that co-creation principles have been incorporated into health service design (Department of Health, 2012; Pūras, 2017). In health service design, co-creation includes and engages key stakeholders, shifting the paradigm from 'experts' knowing and deciding everything, to 'patients' being involved in the decision-making process alongside the 'experts' (Palmer et al., 2018). This collaborative approach ensures that co-creation has greater potential for a strong and enduring health impact, including the setting it was designed to improve (Greenhalgh et al., 2016). Specifically, it is proposed that outputs generated by a co-creation approach are more likely to be 'fit for purpose', acceptable, valuable and enduring, than outputs generated by 'experts' using current approaches (Greenhalgh et al., 2016). At this time, there is limited empirical evidence supporting these assertions (Wiewiora, Keast, \& Brown, 2016), as benefits are difficult to measure and are often only apparent in the long-term (Greenhalgh et al., 2016).

There is general consensus that co-creation with stakeholders in health services is beneficial, but the 'how' and 'why' is still unclear (Gustafsson et al., 2012). In particular, clarity is needed on the specific actions, tools and behaviours that constitute co-creation (Greenhalgh et al., 2016; Witell, Kristensson, Gustafsson, \& Lofgren, 2011). Guidance documents provide some articulation of the 
processes involved in co-creation for health service re-design or quality improvement (Boyd et al., 2010; Cottam \& Leadbeater, 2004; Frow, Nenonen, Payne, \& Storbacka, 2015; Roser, Samson, Humphreys, \& Cruz-Valdivieso, 2009; Spencer, Dineen, \& Phillips, 2013), however there is limited guidance for developing new health services (Boyd et al., 2010).

In summary, co-creation is an approach that is increasingly being adopted in health service design, however there is limited methodological guidance to undertake this work. Participatory action research (PAR) has long been used as a method to engage community members in research and is therefore useful for co-creation operationalisation.

\section{Co-creation using Participatory Action Research (PAR)}

Participatory action research (PAR) is the result of combining two different research forms: action research and participatory research. Briefly, action research involves research that enables action through a cyclic, iterative approach. This involves repeatedly collecting data, reflecting, identifying and solving new problems, building new knowledge and using the results to adapt the intervention (Wadsworth, 1998). This approach involves the intervention constantly being adapted in a corkscrew-like action (Baum, MacDougall, \& Smith, 2006). Participatory research has a focus on structural transformation to address the inequities within society, generally involving vulnerable groups such as women and indigenous peoples (Hall, 1981).

The combination of action research and participatory research therefore involves taking the iterative, spiral framework aspect of action research by involving participants themselves. The participants contribute to the research process, ensuring it is valid and relevant. The participatory research component is included through having a focus on equity and addressing social oppression (Khanlou \& Peter, 2005). PAR engages participants in such a way that they are no longer objects, rather becoming partners in the research process. Participants contribute through selecting the topic to address, data collection, analysis and when research findings are developed, deciding on the next steps (Wadsworth, 1998). While this approach is time consuming and findings can be 
unpredictable, the act of researchers actively engaging with communities can lead to achieving real change to participants' quality of life and wellbeing (Baum et al., 2006). Empowering participants is critical to PAR (Baum et al., 2006; Kelly, 2005).

\section{Older women living alone (OWLA)}

Living alone when older is more prevalent in women than men (Australian Bureau of Statistics, 2017b, 2018; Institute on Aging, 2018; Statista, 2018; U.S. Census Bureau, 2011), with the likelihood of living alone rising with increasing age (Australian Bureau of Statistics, 2017b). Social isolation, financial decline and multiple chronic health conditions all impact negatively on the health and wellbeing of OWLA (Feldman \& Radermacher, 2016). There is limited information describing the health and wellbeing of OWLA and an absence of proven strategies that maximize their wellbeing in the community (Feldman \& Radermacher, 2016). Identification of this gap led us to undertake this project, with the aim of developing ideas for strategies/services that would better meet the needs of OWLA to maintain independence and optimise wellbeing. Given that limited work had been undertaken in this field, we narrowed our scope to the development of new service ideas to address an identified community need, rather than implementation.

\section{Methods}

Given the focus on creating services to address a need for older women living by themselves, instigated by researchers of a service organisation, and including other services, we used the following definition of co-creation: An active, creative and social process, based on collaboration between researchers, service stakeholders and community members, that is initiated by the service to generate value for the community members (Roser et al., 2009). 


\section{Co-creation process}

A toolkit developed in New Zealand for health services was selected to guide the current project process. The toolkit was based in experience-based design principles, led by work in the United Kingdom from the Design Council, the National Health Service Institute of Innovation and Improvement, and UK Department of Health (Boyd, McKernon, Mullin, \& Old, 2012). Experiencebased design focuses on understanding people's experiences of services, identifying those aspects that significantly impact on these experiences, then having community members and staff working to identify improvements and make changes together (Donetto, Tsianakas, \& Robert, 2014). The approach has been used in New Zealand to plan cancer services, improve breast care and melanoma services, develop education programmes for advance care planning and in hospital facilities redesign (Boyd et al., 2012). The six stages are as follows:

- Engage - establishing meaningful relationships with participants

- Plan - establishing goals with participants

- Explore - learning about experiences and identification of improvement ideas

- Develop - work with participants to turn ideas into improvements (or strategies or interventions)

- Decide - choose which improvements to make, and how to make them

- Change - turning the ideas into actions

This approach appeared to support the project to achieve its goals with one proviso: the current project did not include change (implementation). Instead, the plan was to prepare for change by turning improvement ideas with sufficient information to prompt action by key decision makers. Therefore, the framework was adapted as shown in Figure 1.

\section{-Insert Figure 1 here -}

Our planned approach was to use PAR within a series of four two-hour forums, starting with Idea Creation, Development of Idea, Refinement of Idea (OWLA and service stakeholders) and finally Priority Setting. Sessions alternated between OWLA and service stakeholders, with each including 
approximately six to eight participants, as shown in Figure 2. Many lay individuals perceive service stakeholders as 'experts' which may affect equitable contribution from all parties (Delaney, 2018); therefore OWLA and stakeholders were initially separated to enable each group to contribute fully to the process. The PAR approach involved input from participants from each session informing the next session, shaping the ideas generated, until the final service concepts were created.

\section{-Insert Figure 2 here -}

\section{Preparation for co-creation sessions}

Co-creation is predicated on participants being experts of themselves, with this expertise used to inform their contributions to the co-creation process (Janamian, Crossland, \& Wells, 2016). However, this project also sought to develop services using an evidence-base. To ensure OWLA could integrate this evidence into their own personal experiences for discussion, , we incorporated a foundation of information to OWLA and stakeholders involved (O'Brien et al., 2016). We undertook a systematic review of services evaluated to support health and wellbeing in older people, and any barriers to service access, with the full review published elsewhere

). This identified a paucity of robust interventions, with mixed results on effectiveness. Further, while the majority of included participants were female, the interventions were not designed for or in conjunction with women, and none addressed all domains of the Theory of Access; namely accessibility, availability, acceptability, affordability, adequacy and awareness (Saurman, 2015). This indicated that any work needed to consider access and include the end users.

Analysis of ten years of routinely collected data from a large community nursing service identified that a representative group of OWLA in metropolitan Melbourne comprised a mix of sociodemographic factors including age, socio-economic disadvantage, location, education level, country of origin and receipt of home nursing care ( $($ ). This, in conjunction with Australian Census Data (Australian Bureau of Statistics, 2017a, 2017b) guided our inclusion of a representative 
sample of OWLA in interviews, from whom we identified six key barriers and enablers to accessing supports: financial, mobility and ability, transport, knowledge, mental and emotional health and social connection and participation ( $)$. Further, OWLA access to support was also underpinned by their need for trust and security, choice and autonomy, and being treated with dignity and respect by providers.

\section{Idea Creation}

Idea Creation sessions included the Engage, Plan and Explore components of the co-creation process (Boyd et al., 2010). Engaging OWLA commenced with preliminary telephone discussions to obtain consent and organise transport to the discussion venue. OWLA preferred to attend sessions, in a familiar location, close to their own home, rather than in the Central Business District (CBD) as originally planned. Recruitment of participants occurred across all regions of Melbourne, with sessions held in each of these areas in local community centres, as well as a session in the Melbourne CBD. Sessions included key background information to inform participants about issues that needed to be addressed, what the project was trying to achieve, how it would be achieved, who was to be involved, and their role. Further, an outline of the identified barriers for OWLA to access services to maintain independence and wellbeing were presented in infographic form.

Co-creation requires drawing input from the target community to shape the development of a proposed initiative (Janamian et al., 2016). Personas are a technique used to facilitate feedback and allow diverse participants to contribute to the issue being addressed (Al Awar \& Kuziemsky, 2017). We adapted the approach used by Al Awar et al (2017), deriving personas from the barriers and enablers to service access identified from the interviews ( The personas were workshopped by researchers ( $\square$ ), where the first persona was created to include one existing barrier to independence and wellbeing, and each subsequent persona increased in complexity, with four personas in total. The personas involved a brief paragraph outlining the OWLA's circumstances, including the specific goals of the character and barriers faced in achieving them. They also included 
a stock photo, portraying the described character, to personalise the issues and support OWLA attendees to relate to the presented persona. The personas were described to participants in the first session and, with the potential barriers, framed the discussion which facilitated the generation of ways to address the issues raised by the personas. An example of a persona is shown in eAppendix 1.

After this session, the researchers ( service ideas to address the key issues and barriers that are experienced by OWLA. The ideas for services were compiled into groups, which were guided by the access barriers. These were then collated using an infographic style to make them easier to understand and view by participants (see Figure 3 for examples). Guiding questions were brainstormed by (_ to facilitate service stakeholders providing input that would better identify the feasibility of the ideas the OWLA generated and how these ideas might work in practice (see Figure 3).

\section{Development of idea - Stakeholder meeting}

The stakeholder meeting involved discussing the feasibility of integrating ideas generated by the OWLA during their first discussion sessions into the suite of services offered by their own organisation and/or available to the target population(s) serviced by their organisation. The stakeholder meetings were conducted in the CBD. The group were introduced to the project, with description of the personas and the service supports the OWLA generated in the Idea Creation discussion sessions provided. The compiled information was presented, and stakeholder participants were then asked to keep in mind the following foci when considering each idea: Feasibility, Enablers, Barriers and Providers, shown in Figure 3.

\section{-Insert Figure 3 here -}

After this session, two researchers reviewed their notes and the audio files. Prompts were developed to support OWLA to refine their service ideas, based on the input from stakeholders 
about what is needed to develop a service. These were compiled in an infographic style as was presented to the stakeholders, shown in Figure 4. Guiding questions were brainstormed (

) to facilitate OWLA providing input that would further consolidate how the co-created services would operate in practice. This process had four underpinning priorities highlighted as important to older women to consider for any service, as identified from the project interviews and Idea Creation session: trust and security; choice and control; and being treated with dignity and respect, and language shown in Figure 4.

\section{-Insert Figure 4 here-}

\section{OWLA refinement of ideas}

The OWLA participants from the first Idea Creation sessions were invited to further develop and refine ideas for service re-design or new services generated during the initial discussions and refined by the stakeholder group. The infographics on barriers and services co-created for each barrier were used to re-familiarise the OWLA with what was done previously (see Figure 3). We then used the prompts to start to shape the services (see Figure 4), with a view to having sufficient information to operationalise them; going through each service idea one at a time, using these guiding questions.

After this session, two researchers (—) reviewed their notes and the audio files. The OWLA provided some guidance as to what they considered important for process, access, provider and cost for each of the service ideas, given their preferences and based on their experiences and needs. This was compiled into a table, to be presented to the Stakeholders at their next Refinement of Ideas session, shown in Figure 5.

\section{Service stakeholder refinement of ideas}

In this session, we presented the summary of the OWLA contributions to how the services would function in the community. Service stakeholders were asked to review each of the strategies and 
detail that the OWLA generated in the previous discussions. Like the OWLA, we asked the service stakeholders to consider the four areas of process, access, provider and cost for each service idea, given their experiences in providing these services. They were advised that this information would help further consolidate how these services might be operationalised in the community.

\section{-Insert Figure 5 here-}

After this session, the researchers ( combined information from the women and service stakeholders provided information on process, access, provider and cost for each of the service ideas. This was compiled to be presented to the OWLA and Stakeholders at the priority setting sessions.

\section{Priority setting}

The final discussion groups were designed to 'decide' which of the co-created services should be pursued further. The discussion groups were again duplicated and delivered across multiple sites to maximise participation by OWLA and stakeholders. The 'decide' sessions involved prioritising the cocreated services in line with their 'value' to OWLA using Multi-Criteria Decision Analysis (MCDA). Methods and findings from this stage of the project are described in detail elsewhere

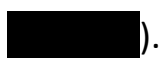

\section{Participants and setting}

In this project, the definition of living alone included women who lived by themselves in premises located in the community. OWLA included women aged 55 years or older; as this age range captures people whose body is physically ageing in advance of chronological age (Levine \& Crimmins, 2018). It also captures OWLA who are too young to access associated services (e.g. aged care) and entitlements (e.g. withdrawing superannuation, pension) that pension-aged individuals are eligible for, despite having the potential need. 
Anticipating that needs and preferences of OWLA will vary depending upon age, education, culturally and linguistically diverse (CALD) status or other individual characteristics, we recognised that it may be difficult to develop services that respect this variation and are tailored to the different needs and preferences of different groups. Therefore, we limited participation to those who were English-speaking. To reflect the English-speaking OWLA community, women of different ages, education levels, from varying regions of metropolitan Melbourne were invited to participate in the co-creation process. These were primarily women who had participated in the interviews described above and indicated interest in further involvement in the project; or women who had not been able to take part due to scheduling conflicts. These women were contacted by phone or email and after agreement was obtained, an information sheet and consent form were provided by email or post before the first forum. The women provided informed consent and were either reimbursed for their travel expenses or provided transport to attend.

Service stakeholders were drawn from established links with health and aged care services in the community, primary care, sub-acute and acute care sectors. A range of service providers was targeted to ensure that a variety of perspectives were included. Participants provided informed consent.

The researchers had academic psychology and sociology ( $\square$ ), clinical allied health ( $\square$ ) and academic health economic ( ) backgrounds. Each session was facilitated, audiotaped, with notes taken by members of the research team present during each forum. Approval was provided by the Human Research Ethics Committee of the relevant organisations. 


\section{Results}

\section{Participants}

A total of 13 women living alone, aged 55 years or more, and 11 stakeholders comprising representatives from service providers and advocacy groups, were recruited to participate. All stakeholders were female. Researchers included four women and two men (Table 1).

\section{-Insert Table 1 here-}

\section{OWLA Idea Creation sessions}

There was robust discussion amongst the participants stimulated by the personas, with each OWLA raising their own personal experiences relating to the characters. Fourteen ideas were generated by OWLA for services to help maintain independence and optimise wellbeing, and collated by the research team, shown in Table 2.

\section{-Insert Table 2 here-}

\section{Service stakeholder development of ideas}

Stakeholders identified four of the proposed services that should not proceed due to feasibility issues, leaving 10 services to pursue. These excluded services and issues leading to their exclusion are identified in Table 3.

\section{-Insert Table 3 here-}

The combined information from the women and service stakeholders provided information on process, access, provider and cost for each of the 10 service ideas, shown in e-Appendix 2.

\section{Priority setting}

The MCDA process identified three service ideas prioritised by the OWLA and service stakeholders: 
Handy Help, Exercise Buddies and Volunteer Drivers.

\section{Discussion}

Through an iterative process of co-creation, involving OWLA, key service stakeholders and researchers, we collectively developed service ideas to support OWLA maintain independence and optimise wellbeing. The process used an existing framework and PAR and culminated in 14 cocreated services, with 10 being considered feasible and meeting previously unmet needs and preferences of a growing segment of the population. Participants then prioritised the top three to focus on first: Handy Help, Exercise Buddies and Volunteer Drivers. Different approaches have been proposed to engage with key stakeholders to facilitate their input in the process of service design, and ensure it is meaningful and feasible to address the identified need (Bovaird \& Loeffler, 2012). However, there is little published about how to operationalise these approaches (Osborne, Radnor, \& Strokosch, 2016). We believe that our work begins to address this.

Co-creation frameworks typically begin with an identified issue that they seek to improve (Donetto et al., 2014), or a product that they want to make to address an identified issue (O'Brien et al., 2016). Our approach commenced earlier on in the process, triggered by identification of a goal to maintain independence and optimise wellbeing with a population group at increased risk of poor outcomes, OWLA. These issues were identified by Feldman \& Radermacher (2016) who also identified key gaps in understanding the OWLA profile, barriers and enablers to accessing support, and what services or strategies were effective. We dedicated time to address each of these key knowledge gaps. Developing the evidence-base was essential to provide the foundation for all stakeholders to understand the issues and thereby to contribute meaningfully by generating ideas to address them.

Previous studies have used systematic reviews and interview data to guide content and structure of a new technology product to be co-designed with community members, generally using design tools 
and emphasising the design aspects (O'Brien et al., 2016). The present study focused on value creation for community members and service stakeholders, using a similar approach, which required significant preliminary research, including a systematic review. Recruitment of a representative sample for interviews was informed by extensive analysis of routinely collected data from a health and aged care service. Face-to-face interviews with OWLA provided a more detailed understanding of barriers and enablers to service access and achieving independence and wellbeing. Compiling these various sources of information was done in a way to personalise the information and make it understandable to OWLA from different literacy levels through personas (Al Awar \& Kuziemsky, 2017). The whole approach took considerable time and resources, however as a result, we were able to rely on evidence rather than assumptions to guide the co-creation process.

\section{Practical learnings}

Supporting engagement of OWLA necessitated going to participants, to locations they were comfortable getting to, and were in a familiar environment. This is not a new finding. Older people have previously indicated that physical access to services can be problematic, and there was a need to have local venues so that travel could be minimised (Dow, Sparrow, Moore, Gaffy, \& Yates, 2013). As we sought to develop services that would meet the needs of the broader OWLA population, we needed to include a representative sample of English-speaking OWLA across metropolitan Melbourne. This required multiple smaller meetings in small, community venues, thereby increasing the time involved to organise and collect the information. However, this increased participation by our target group, and included those community members that might not normally be engaged in such initiatives.

The aim of this project was to co-create services that addressed barriers to OWLA accessing support services to ultimately maintain independence and optimise wellbeing: co-creating services of value to both OWLA and potential service providers. To do this OWLA needed to drive what those 
services needed to be. To that end, most of the discussion sessions involved OWLA and service stakeholders separately. The concern was that the service stakeholders, by being seen as 'experts,' would limit the engagement of OWLA. While there is a push for collaboration in health and social care, there is still a hierarchical structure in place, where the professionals are perceived as allknowing and the service recipients as those needing guidance by these professionals (Janamian et al., 2016). Therefore, the project was led by the input from the OWLA, with the stakeholders providing input on the realities of service delivery application and ensuring what was put forward by OWLA was not already available.

To extend the input of OWLA, targeted facilitation that led participants to consider what issues they and their peers have in the community, and what could be done to address them was needed. This was done by initiating discussion through the use of stories about older women, developed from the interview data collected as part of this work ( ). These developed personas were used to guide participants in identifying what could support the persona in achieving their goal of maintaining independence and wellbeing. In this way, focusing the discussions on the identified issues, but in a way that encouraged them to interact and contribute their own experiences in forming ideas for services. Stories of target groups have been used to promote discussions on advance care planning with cancer patients and caregivers, and proposed as a way to successfully initiate sensitive conversations that would engage participants (Michael, O'Callaghan, \& Clayton, 2016). There is always the concern that a guided approach would constrain the input by the target group, so that potential ideas may not be raised. Yet there is a need to focus the input by community members so that the targeted issues are adequately addressed. This tension needs greater exploration, with the development of multiple strategies to draw from so that individuals who may feel constrained in contributing their full potential be harnessed using different means. In addition, work is needed to develop methods to identify when techniques constrain individuals from contributing to their full potential. 
The ideas generated by OWLA were then collated and presented to key stakeholders to ascertain from them whether these interventions were feasible, and how they might work within the current system. While this group are more accustomed to focusing their input to address the topic at hand, they are also embedded within a structured system in which they are familiar and are comfortable with the current status quo. Accepting and making change is difficult for service providers (Nembhard, Alexander, Hoff, \& Ramanujam, 2009), and considering options outside of traditional, accepted approaches may also be more difficult due to their potential for failure (Nembhard et al., 2009). This might lead stakeholders to be more critical of non-traditional approaches and lead them to identify greater barriers to prevent their acceptance and pursuit; although the barriers raised were problematic and very difficult to overcome. The four OWLA ideas that were not pursued may have suffered from this.

\section{Strengths and Limitations}

Our approach used an evidence base and active recruitment of a representative sample of the community to participate in the co-creation sessions. Further, a multidisciplinary team with expertise in a range of research methodologies, including systematic reviewing, qualitative enquiry, and intervention co-design and development was involved. These lend strength to the end result. However some limitations must be considered.

The approach used to draw ideas from participants, involving stakeholders to contribute by considering feasibility, may have limited exploration of less traditional strategies that the OWLA raised. Further work to refine the approach is warranted.

The sample selection approach employed in the present study was designed to recruit a representative sample of English speaking OWLA of varied education level and age, so is not representative of the needs and preferences of other age groups, CALD status, or other individual characteristics. Australian Census Data (Australian Bureau of Statistics, 2017a, 2017b) identified that 
there are significant older people with a primary level of education, while participants in our cocreation process had secondary education and higher; so further work is needed to elucidate whether education level may be a barrier to participation by older women in this process. In addition, due to the significant different needs of diverse populations, further work is required to develop services that are responsive to the needs and preferences of OWLA from all sub-groups across metropolitan Melbourne (particularly those from varied cultural and linguistic backgrounds).

\section{Conclusion}

This work adds to the knowledge base in the co-creation of health and social services, initiated because of an evidence-based identified community need. We used a systematic process, comprising a foundation of evidence, then input firstly from OWLA, followed by service providers and experts with knowledge and experience of this cohort and addressing their needs. This approach culminated in the creation of 10 services with potential value for community members and service stakeholders reflecting the unmet needs and preferences of a growing segment of the population, with the top three to be pursued first: Handy Help, Exercise Buddies and Volunteer Drivers. Future research will build on this co-creation approach, to continue the engagement of OWLA and other key stakeholders to develop these priority services, to ensure the unmet needs of this vulnerable population are addressed. We anticipate that this approach would be useful to address unmet needs of other vulnerable groups. 


\section{References}

Al Awar, Z., \& Kuziemsky, C. (2017). Persona Development and Educational Needs to Support Informal Caregivers. Studies in Health Technology and Informatics, 235, 373-377.

Australian Bureau of Statistics. (2013). IRSD (2033.0.55.001). Retrieved from http://www.abs.gov.au/ausstats/abs@.nsf/Lookup/2033.0.55.001main+features100052011 Australian Bureau of Statistics. (2017a). Ageing Population, 2016. Canberra Retrieved from http://www.abs.gov.au/ausstats/abs@.nsf/Lookup/by\%20Subject/2071.0 2016 Main\%20F eatures $\sim$ Ageing\%20Population 14.

Australian Bureau of Statistics. (2017b). Census of Population and Housing: Reflecting Australia Stories from the Census, 20162071.0

Australian Bureau of Statistics. (2018). Census of Population and Housing: Estimating homelessness, 2016. (2049.0). Canberra Retrieved from http://www.abs.gov.au/ausstats/abs@.nsf/PrimaryMainFeatures/2049.0.

Baum, F., MacDougall, C., \& Smith, D. (2006). Participatory action research. Journal of epidemiology and community health, 60(10), 854-857. doi:10.1136/jech.2004.028662

Bovaird, T., \& Loeffler, E. (2012). We're all in this together: User and community co-production of public outcomes: Discussion Paper. Retrieved from https://www.birmingham.ac.uk/Documents/college-social-sciences/governmentsociety/inlogov/discussion-papers/inlogov-co-production-chapter.pdf

Boyd, H., McKernon, S., Mullin, B., \& Old, A. (2012). Improving healthcare through the use of codesign. The New Zealand Medical Journal, 125(1357), 76-87.

Boyd, H., McKernon, S., \& Old, A. (2010). Health service co-design: Working with patients to improve healthcare and services - guide and toolkit. Retrieved from http://www.healthcodesign.org.nz/ 
Cottam, H., \& Leadbeater, C. (2004). RED paper 01: Health: Co-creating services. Retrieved from https://www.designcouncil.org.uk/sites/default/files/asset/document/red-paper-health.pdf

Delaney, L. (2018). Patient-centred care as an approach to improving health care in Australia. Collegian, 25(1), 119-123. doi:10.1016/j.colegn.2017.02.005

Department of Health. (2012). Liberating the NHS: no decision about me without me. National Health Service, Retrieved from http://webarchive.nationalarchives.gov.uk/20130105002025/http://www.dh.gov.uk/prod c onsum dh/groups/dh digitalassets/@dh/@en/documents/digitalasset/dh 134218.pdf

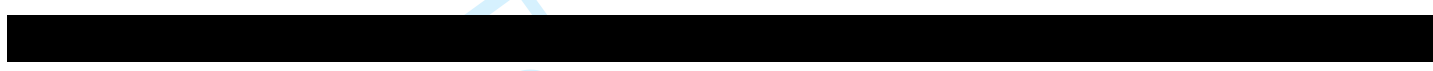

Donetto, S., Tsianakas, V., \& Robert, G. (2014). Using Experience-based Co-design (EBCD) to improve the quality of healthcare: mapping where we are now and establishing future directions: Final Report. Retrieved from https://www.kcl.ac.uk/nursing/research/nnru/publications/reports/ebcd-where-are-wenow-report.pdf

Dow, B., Sparrow, P., Moore, K., Gaffy, E., \& Yates, I. (2013). What do older Australians want? Australasian Journal on Ageing, 32(4), 236-240. doi:10.1111/ajag.12040

Feldman, S., \& Radermacher, H. (2016). Time of our lives? Building opportunity and capacity for the economic and social participation of older Australian women. Retrieved from https://www.Imcf.org.au/getmedia/23a2ebd6-b2dc-48b1-bc81-59e1bc0f27cd/2016-03-07$\underline{\text { LMCF-Time-of-Our-Lives-Report.pdf.aspx }}$

Frow, P., Nenonen, S., Payne, A., \& Storbacka, K. (2015). Managing Co-creation Design: A Strategic Approach to Innovation. British Journal of Management, 26, 463-483. doi:10.1111/14678551.12087 
Greenhalgh, T., Jackson, C., Shaw, S., \& Janamian, T. (2016). Achieving Research Impact Through Cocreation in Community-Based Health Services: Literature Review and Case Study. The Milbank Quarterly, 94(2), 392-429.

Gustafsson, A., Kristensson, P., \& Witell, L. (2012). Customer co-creation in service innovation: a matter of communication? Journal of Service Management, 23(3), 311-327. doi:10.1108/09564231211248426

Hall, B. (1981). Participatory research, popular knowledge and power: A personal reflection. Convergence, 14(3), 6-19.

Iliffe, S., Kharicha, K., Harari, D., Swift, C., Gillmann, G., \& Stuck, A. E. (2007). Health risk appraisal in older people 2: the implications for clinicians and commissioners of social isolation risk in older people. The British Journal of General Practice, 57(537), 277-282.

Institute on Aging. (2018). Living alone. Retrieved from https://www.ioaging.org/aging-inamerica\#livingalone

Janamian, T., Crossland, L., \& Wells, L. (2016). On the road to value co-creation in health care: the role of consumers in defining the destination, planning the journey and sharing the drive. Medical Journal of Australia, 204(7 Supplemental), S12. doi:10.5694/mja16.00123

Kelly, P. J. (2005). Practical Suggestions for Community Interventions Using Participatory Action Research. Public Health Nursing, 22(1), 65-73. doi:10.1111/j.0737-1209.2005.22110.x

Khanlou, N., \& Peter, E. (2005). Participatory action research: considerations for ethical review. Social Science \& Medicine, 60(10), 2333-2340. doi:https://doi.org/10.1016/j.socscimed.2004.10.004 
Levine, M. E., \& Crimmins, E. M. (2018). Is 60 the New 50? Examining Changes in Biological Age Over the Past Two Decades. Demography, 55(387). doi:https://doi.org/10.1007/s13524-017$\underline{0644-5}$

Michael, N., O'Callaghan, C., \& Clayton, J. M. (2016). Exploring the utility of the vignette technique in promoting advance care planning discussions with cancer patients and caregivers. Patient Education and Counseling, 99(8), 1406-1412. doi:https://doi.org/10.1016/j.pec.2016.03.021
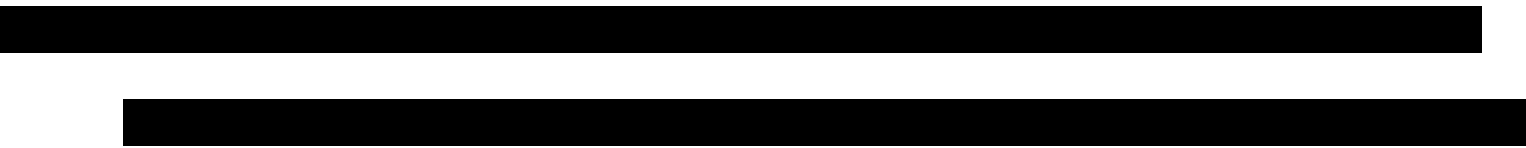

Nembhard, I. M., Alexander, J. A., Hoff, T. J., \& Ramanujam, R. (2009). Why Does the Quality of Health Care Continue to Lag? Insights from Management Research. Academy of Management Perspectives, 23(1), 24-42. doi:10.5465/AMP.2009.37008001

O'Brien, N., Heaven, B., Teal, G., Evans, E. H., Cleland, C., Moffatt, S., . . Moynihan, P. (2016). Integrating Evidence From Systematic Reviews, Qualitative Research, and Expert Knowledge Using Co-Design Techniques to Develop a Web-Based Intervention for People in the Retirement Transition. Journal of Medical Internet Research, 18(8), e210.
\end{abstract}

Osborne, S. P., Radnor, Z., \& Strokosch, K. (2016). Co-Production and the Co-Creation of Value in Public Services: A suitable case for treatment? Public Management Review, 18(5), 639-653. doi:10.1080/14719037.2015.1111927

Palmer, V. J., Weavell, W., Callander, R., Piper, D., Richard, L., Maher, L., . . Robert, G. (2018). The Participatory Zeitgeist: an explanatory theoretical model of change in an era of coproduction and codesign in healthcare improvement. Medical Humanities. doi:10.1136/medhum-2017011398 
Pūras, D. (2017). Report of the Special Rapporteur on the right of everyone to the enjoyment of the highest attainable standard of physical and mental health. Retrieved from https://documents-ddsny.un.org/doc/UNDOC/GEN/G17/076/04/PDF/G1707604.pdf?OpenElement

Roser, T., Samson, A., Humphreys, P., \& Cruz-Valdivieso, E. (2009). Co-creation: New Pathways to Value: An Overview. Retrieved from http://www.portugalglobal.pt/PT/RoadShow/Documents/2016/GuimaraesCo creationNewP athways to value An overview.pdf

Saurman, E. (2015). Improving access: modifying Penchansky and Thomas's Theory of Access. Journal of Health Services Research \& Policy, 21(1), 36-39. doi:10.1177/1355819615600001

Spencer, M., Dineen, R., \& Phillips, A. (2013). Co-producing services-Co-creating health. Retrieved from http://www.1000livesplus.wales.nhs.uk/sitesplus/documents/1011/t4i\%20\%288\%29\%20coproduction.pdf

Statista. (2018). Number of people living alone in the United Kingdon (UK) 2017, by age and gender (in 1,000)*. Retrieved from https://www.statista.com/statistics/281616/people-living-alonein-the-united-kingdom-uk-by-age-and-gender/

The King's Fund. (2013). Experience-based co-design toolkit. Retrieved from https://www.kingsfund.org.uk/projects/ebcd

U.S. Census Bureau. (2011). Sixty-five plus in the United States. Retrieved from https://www.census.gov/population/socdemo/statbriefs/agebrief.html

Vargo, S. L., \& Lusch, R. F. (2004). Evolving to a New Dominant Logic for Marketing. Journal of Marketing, 68(1), 1-17. doi:10.1509/jmkg.68.1.1.24036

Wadsworth, Y. (1998). What is Participatory Action Research? ,. Action Research International, Paper 2. 
WHO. (2015). World Report on Ageing and Health. Retrieved from Geneva:

\section{http://www.who.int/ageing/publications/world-report-2015/en/}

Wiewiora, A., Keast, R., \& Brown, K. (2016). Opportunities and Challenges in Engaging Citizens in the Co-Production of Infrastructure-Based Public Services in Australia. Public Management Review, 18, 483-507.

Witell, L., Kristensson, P., Gustafsson, A., \& Lofgren, M. (2011). Idea generation: customer cocreation versus traditional market research techniques. Journal of Service Management, 22(2), 140-159. 
Table 1. Details of participants

\begin{tabular}{|c|c|c|}
\hline & OWLA & Stakeholders \\
\hline Age, M (SD) & $72(8.7)$ & $54(12.9)$ \\
\hline Born in Australia, n (\%) & $10(77 \%)$ & $10(91 \%)$ \\
\hline \multicolumn{3}{|l|}{ Education, $\mathrm{n}(\%)$} \\
\hline Primary & $0(0 \%)$ & $0(0 \%)$ \\
\hline Secondary & $6(46 \%)$ & $0(0 \%)$ \\
\hline Undergraduate & $6(46 \%)$ & $3(27 \%)$ \\
\hline Postgraduate & $1(8 \%)$ & $7(64 \%)$ \\
\hline Socioeconomic Status^ M (SD) & $7.4(2.6)$ & $8(1.7)$ \\
\hline
\end{tabular}


Table 2. Co-created ideas from OWLA collated after the Ideas Creation sessions.

\begin{tabular}{|c|c|c|}
\hline & Ideas raised by OWLA & Details of ideas raised by OWLA \\
\hline \multicolumn{3}{|c|}{ Mobility and ability } \\
\hline 1. & In home services & $\begin{array}{l}\text { Paid program with callouts to OWLA for small household tasks } \\
\text { not addressed by council services (e.g., window cleaning, } \\
\text { mattress flipping) }\end{array}$ \\
\hline 2. & $\begin{array}{l}\text { Medical support post } \\
\text { procedure }\end{array}$ & $\begin{array}{l}\text { Post-discharge hotel stay for OWLA (similar to post-partum, } \\
\text { nurse on call) }\end{array}$ \\
\hline 3. & Exercise support & $\begin{array}{l}\text { Buddy system for (rehabilitation) exercise, in person or over } \\
\text { video }\end{array}$ \\
\hline \multicolumn{3}{|c|}{ Transport } \\
\hline 4. & Transport volunteers & $\begin{array}{l}\text { Volunteer driver pool service to go to activities more than } \\
\text { medical appointments }\end{array}$ \\
\hline 5. & Transport volunteers 2 & $\begin{array}{l}\text { Extension of health service/hospital volunteer program to go to } \\
\text { activities more than medical appointments }\end{array}$ \\
\hline \multicolumn{3}{|c|}{ Social connections/Participation } \\
\hline 6 . & Social connection services & Groups for housebound individuals over the telephone/video \\
\hline 7. & $\begin{array}{l}\text { Neighbourhood social } \\
\text { connections }\end{array}$ & Community friendly visitor program - screened \\
\hline 8. & Social connections using mail & $\begin{array}{l}\text { Letter from council prompting community members to check in } \\
\text { with neighbours }\end{array}$ \\
\hline \multicolumn{3}{|c|}{ Financial } \\
\hline
\end{tabular}




\begin{tabular}{|l|l|l|}
\hline 9. & Share housing & Communal housing for older individuals \\
\hline 10. & Donations & Business to donate materials for activities and hobbies \\
\hline 11. & Generate income & Part time work through skill matching with other community \\
members who have a need
\end{tabular}


Table 2. Ideas created by OWLA and rejected by service stakeholders.

\begin{tabular}{|c|c|}
\hline Rejected Ideas & Reasons for rejection \\
\hline $\begin{array}{l}\text { Transport volunteers 2: } \\
\text { Extension of health } \\
\text { service/hospital volunteer } \\
\text { program to go to activities } \\
\text { more than medical } \\
\text { appointments }\end{array}$ & $\begin{array}{l}\text { Not be feasible within the current structure of hospital- } \\
\text { based volunteer drivers process; money, occupational } \\
\text { health and safety/after hours }\end{array}$ \\
\hline $\begin{array}{l}\text { Social connection services: } \\
\text { Groups for housebound } \\
\text { individuals over the } \\
\text { telephone/video }\end{array}$ & $\begin{array}{l}\text { Holding group sessions was considered fraught with } \\
\text { technological barriers, with stakeholders citing multiple } \\
\text { occasions when technology failed, and the likelihood of the } \\
\text { causes of failure (generally National Broadband } \\
\text { Network/internet connectivity issues) unable to change, the } \\
\text { logistics of providing such a service was deemed unfeasible }\end{array}$ \\
\hline $\begin{array}{l}\text { Donations: } \\
\text { Business to donate materials } \\
\text { for activities and hobbies }\end{array}$ & $\begin{array}{l}\text { Donations would require significant storage; getting items } \\
\text { to the appropriate community members will necessitate } \\
\text { significant logistical requirements; and while many } \\
\text { businesses are supportive and will donate for a good cause, } \\
\text { many will likely use this opportunity to donate items they } \\
\text { can no longer use, but aren't useful for the target } \\
\text { community members. Based on the input, the logistics of } \\
\text { providing such a service was deemed too difficult }\end{array}$ \\
\hline Increase family/friend's & This was considered unfeasible to target family/friends of \\
\hline
\end{tabular}




\begin{tabular}{|l|l|}
\hline awareness of services for & $\begin{array}{l}\text { OWLA, as there is currently no way these groups could be } \\
\text { OWLA }\end{array}$ \\
\hline
\end{tabular}


Tables title list:

Table 1. Details of co-creation participants.

Table 2. Co-created ideas from OWLA collated after the Ideas Creation sessions.

Table 3. Ideas created by OWLA and rejected by service stakeholders. 


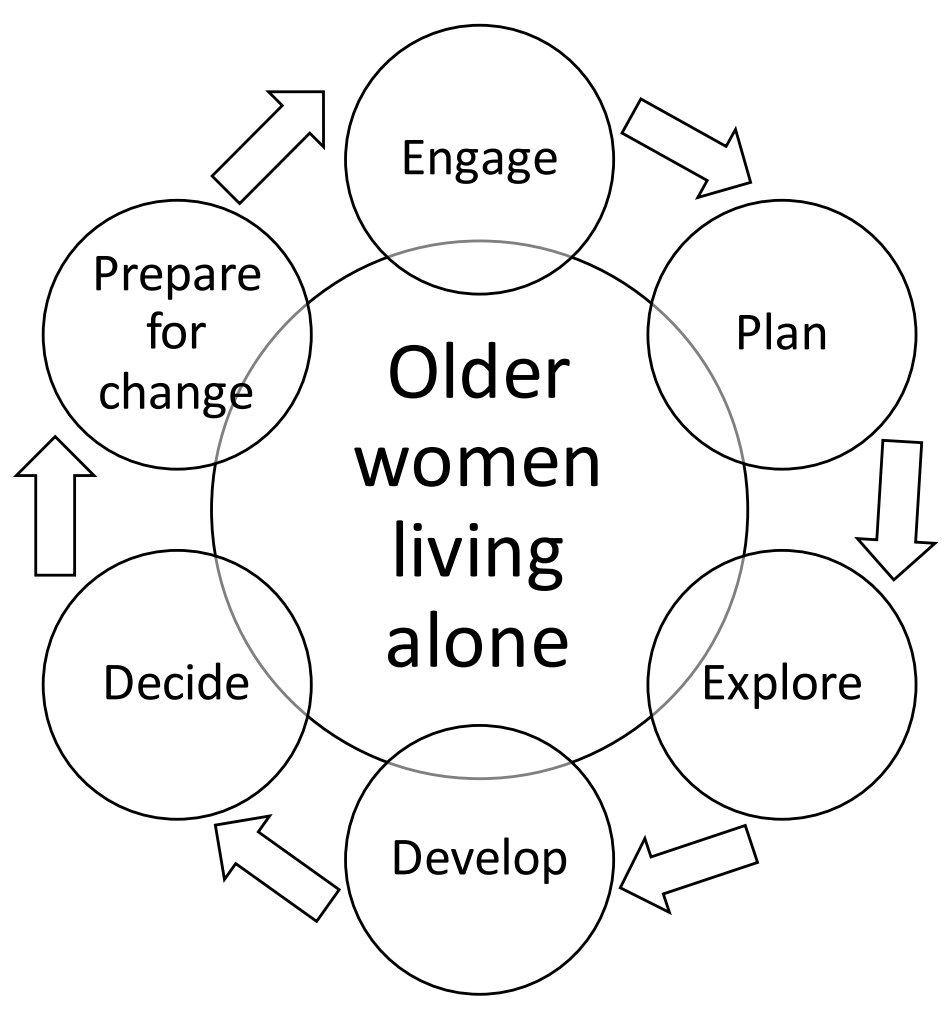

Figure 1. Co-creation approach, adapted from (Boyd et al., 2010). 


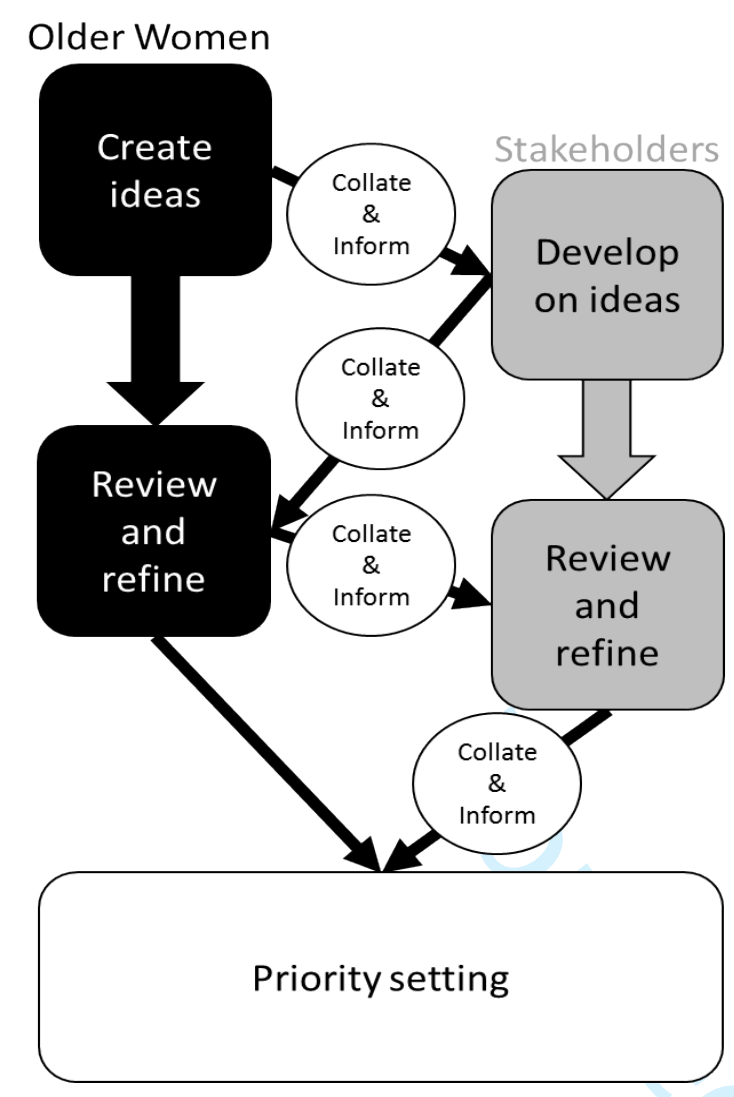

Figure 2. Co-creation forums - planned structure. 


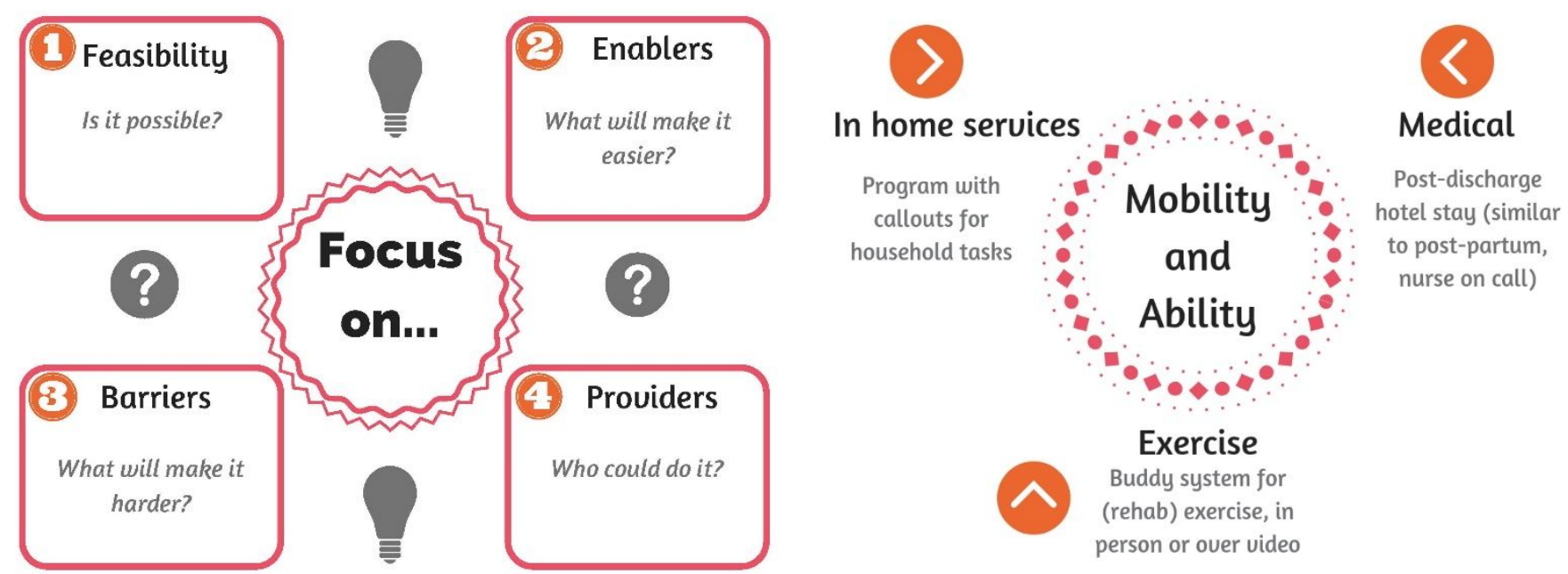

Figure 3. Key foci service stakeholders discussed in the forums and an example of how services to address a barrier were presented. 


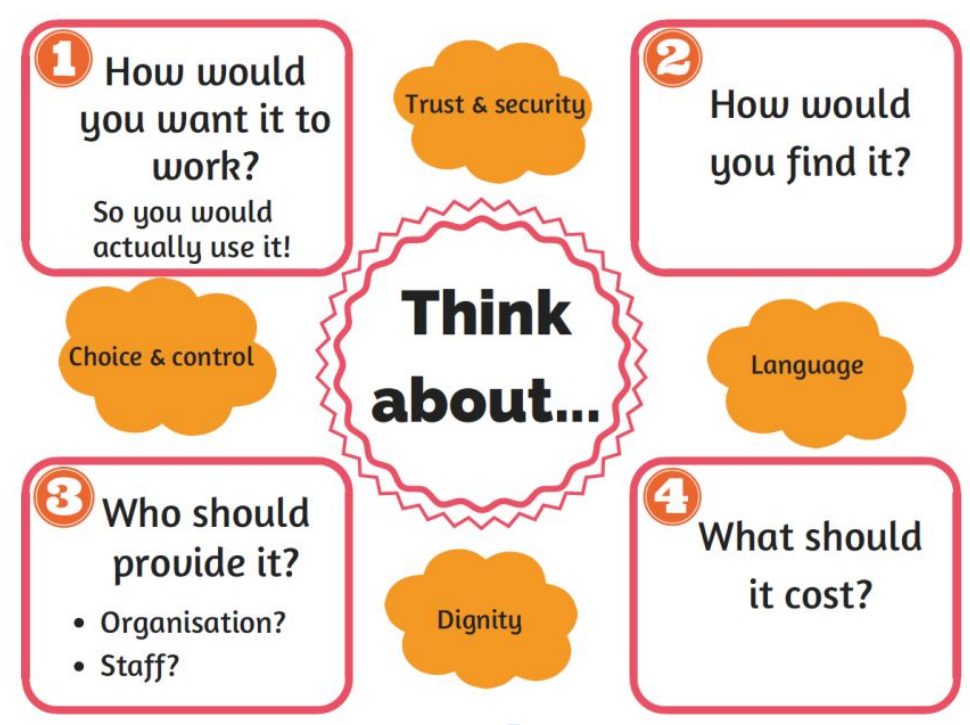

Figure 4. Prompts for OWLA and stakeholders to more fully articulate how a service could be operationalised. 


\section{Mobility and Ability \\ In home services - household tasks}
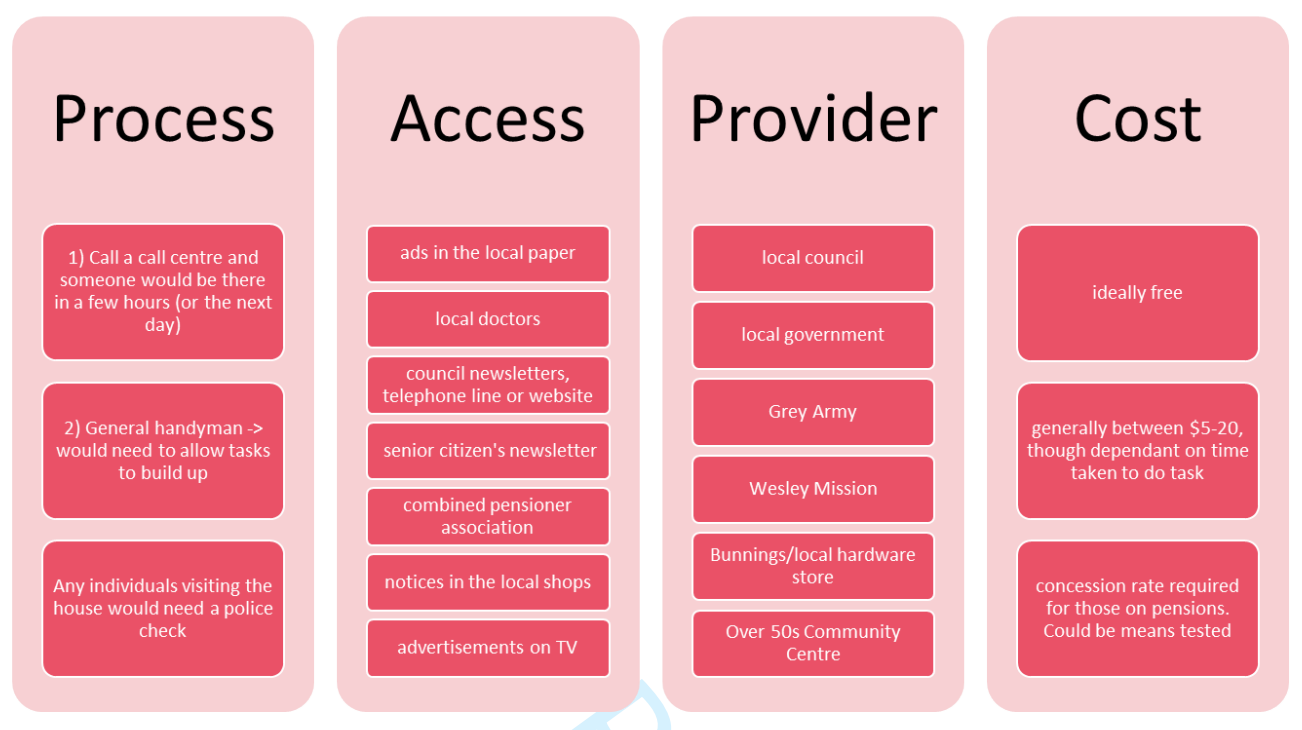

Figure 5. Example of OWLAs input re: how a new service to provide support for in home household tasks might function. 
Figure caption list

Figure 1. Co-creation approach, adapted from (Hilary Boyd et al., 2010).

Figure 2. Co-creation forums - planned structure.

Figure 3. Key foci service stakeholders discussed in the forums and an example of how services to address a barrier were presented.

Figure 4. Prompts for OWLA and stakeholders to more fully articulate how a service could be operationalised.

Figure 5. Example of OWLAs input re: how a new service to provide support for in home household tasks might function. 